\title{
Chilling-induced DNA Demethylation is associated with the cold tolerance of Hevea brasiliensis
}

\author{
Xiao Tang ${ }^{\dagger}$, Qichao Wang ${ }^{\dagger}$, Hongmei Yuan and Xi Huang ${ }^{*}$ (i)
}

\begin{abstract}
Background: Low temperature influences the development and latex production of rubber trees (Hevea brasiliensis) when extension to suboptimal high-latitude areas. The successful extension of Hevea brasiliensis cultivation to highlatitude areas has long believed to benefit from the breeding of cold-tolerant cultivars. A puzzling incongruity is the variation in cold tolerance among the cultivated clones despite their similar genetic make-up.

Results: To investigate this, we first transferred cultivar Reyan 7-33-97 to short-term cold treatment, and showed that cold-related genes (such as HbICE1 and HbCBF2), cold-responsive (COR) genes, and DNA-methylation related genes (such as HbMET1) were induced by cold treatment. Furthermore, long-term cold treatment not only elevated the transcriptional activities of the HbICE1, HbCBF2, and HbMET, but also induced DNA demethylation of their promoters. Cold treatment increased the transcriptional activities of demethylation-related genes such as the HbDME, HbROS, and HbDML genes, but did not alter the promoter methylation status. Furthermore, the HblCE1 and HbMET promoters showed hypomethylation status in samples collected at the end of winter from 12 different cultivars grown in four geographical locations, but switched to hypermethylation status at the end of summer. Expression of COR was correlated with the low temperature. Given that little genetic diversity exists in the HbICE1 and HbMET promoters among different cultivars, the DNA demethylation induced by cold was highly correlated with low temperature, but not with the genetic backgrounds of cultivars.
\end{abstract}

Conclusion: Cold-induced epigenetic modification might play an important role in cold tolerance of $H$. brasiliensis.

Keywords: Hevea brasiliensis, Cold tolerance, DNA demethylation, HbICE1, HbMET

\section{Background}

Hevea brasiliensis Muell. Arg. is the major source of commercial natural rubber and is native to the rainforests of tropical regions of the Amazonian basin. In 1876, Henry Wickham collected 70,000 seeds of rubber tree in Brazil and smuggled to England. The seedlings, known as 'Wickham base', were later sent to Southeast Asian countries and became the major germplasm for selection of rubber cultivars [1]. In the late 1970s, rubber plantations spread to sub-optimal environments worldwide; e.g. southern China, southern Brazil, highland areas of Vietnam, and northeast India. These areas have diverse climates and environmental

\footnotetext{
* Correspondence: xihuang@hainu.edu.cn

${ }^{\dagger}$ Equal contributors

Hainan Key Laboratory for Sustainable Utilization of Tropical Bioresources, Institute of Tropical Agriculture and Forestry, Hainan University, Renmin Rd. 58, Haikou 570228, People's Republic of China
}

stresses, such as low temperature, high latitude, disease, drought, and so on. A number of rubber clones were developed to exhibit specific adaptation to these areas. While RRIM 600 is a universally adapted clone in these suboptimal areas, the RRII 208, RRII 203, PB 235, and Haiken 1 (India); GT 1 (Vietnam); Reyan 7-33-97 and PB 235 (China); and FX-3864 and PB 235 (Brazil) clones exhibit specific adaptations for yield in different countries [2]. Low temperature influences not only the latex production but the development of rubber trees and limits development of rubber plantations in high-latitude areas. Lower temperatures are also responsible for stopping rubber production for 2-3 months per year in sub-optimal areas [3, 4]. Therefore, breeding clones with enhanced cold tolerance is of great significance.

Low temperature is one of the most limiting factors for plants. Plants adapt to seasonal temperature oscillations 
by adjusting their metabolism and changing the content of a range of cryo-protective compounds to enhance their cold tolerance. Major step to elucidate the signalling networks of cold-stress response is characterization of Crepeat-binding factors (CBFs) and dehydration-responsive element-binding factors 1 (DREB1s) [5-8]. Inducer of CBF expression 1 (ICE1) and calmodulin binding transcription activator 3 (CAMTA3) positively regulates the expression of $C B F$ genes [5, 9]. Whereas MYB15 and ethylene insensitive 3 (EIN3) are negative regulators of CBF genes [10, 11], brassinazole-resistant 1 (BZR1) positively regulates freezing tolerance by acting upstream of $C B F 1$ and $C B F 2$ to directly regulate their expression [12]. Most recently, phytochrome-interacting factor 3 (PIF3) has been shown to function as a negative regulator of Arabidopsis freezing tolerance by directly binding to the promoters of CBF genes to inhibit their expression [13]. Besides transcriptional regulation, several factors regulate ICE-CBF pathway at posttranslational levels. For example, SIZ1 (SAP and Miz1) was reported to mediate sumoylation of ICE1 and up-regulate CBF3 expression [14]. In contrast, RING E3 ligase, HOS1 (high expression of osmotically responsive genes1) negatively regulate plant cold responses via mediating the ubiquitination and degradation of ICE1 [15]. A recently identified kinase, open stomata 1 (OST1), phosphorylated and stabilized ICE1, and promoted the expression of CBF expression and freezing tolerance [16]. Other protein kinases, such as mitogen-activated protein kinases MPK3 and MPK6, have been implicated in phosphorylate the ICE1 protein to negatively regulates ICE1 stability and freezing tolerance in Arabidopsis [17]. Liu et al. demonstrated that the cold-activated plasma membrane CRPK1 phosphorylates 14-3-3 proteins, which are imported from the cytosol to the nucleus promote the degradation of CBFs via the 26S proteasome pathway [18]. The ICE-CBF transcriptional cascade was proposed to play a central role in cold responses of plants [19].

A growing body of evidence reveals that epigenetic modifications (e.g. DNA methylation and histone modifications) play an important role in regulation of stressresponsive genes in plants [20-23]. Epigenetic mechanisms can bring about heritable phenotypic changes by regulating gene expression without changing DNA sequences [24, 25]. DNA cytosine methylation is an evolutionarily conserved chromatin modification that contributes to gene regulation and genome structure and integrity [26]. In plants, cytosine methylation occurs at CG, CHG, and CHH sites (where $\mathrm{H}$ represents A, C, or T) $[27,28]$. Plants encode diverse DNA methyltransferases that specially target cytosines for methylation in specific DNA sequence contexts, including DOMAINS REARRANGED METHYLTRANSFERASE 2 (DRM2), the CHROMOMETHYLASES (CMTs), and METHYLTRANSFERASE 1
(MET1) [29]. Cytosine methylation is established and maintained by METs using S-adenosyl-L-methionine (SAM) as the methyl donor. Maintenance of DNA methylation in CG and CHG contexts is mediated by MET1 and CMT3, respectively [27]. CMT2 in Arabidopsis was found to be associated with differential $\mathrm{CHH}$ methylation in transposable elements [30]. CMT3 is required for the establishment of gene body methylation [26]. Cytosine methylation of asymmetric $\mathrm{CHH}$ context can't be maintained and just de novo mediated by DRM2 protein during every cell cycle [31, 32]. Pre-existing DNA methylation can be lost in passive or active demethylation processes. Passive demethylation occurs when failure to maintain DNA methylation owing to a shortage of methyl groups or dysfunction of DNA methyltransferase, whereas active removal of cytosine methylation is catalysed by the DNA glycosylase family, such as demeter (DME) and their paralogs demeter-like (DML2 and DML3) proteins, and repressor of silencing 1 (ROS1) [27, 33-35].

Expression of many epigenetic regulators is regulated by low temperature. In Arabidopsis, HDA6 has been identified as a putative histone deacetylase needed to enhance DNA methylation induced by double-stranded RNA [36]. HDA6 is induced by long-term cold treatment, and regulates locus-directed heterochromatin silencing in cooperation with MET1, possibly recruiting MET1 to specific loci [37]. RDM4 (RNA-directed DNA methylation 4) modulates cold-stress resistance through the CBF-mediated pathway in Arabidopsis [20]. Expression of $H D A C$ genes was increased after cold acclimation, and global deacetylation of histone ( $\mathrm{H} 3$ and $\mathrm{H} 4)$ was observed in maize [38]. Moreover, tandem repeats in heterochromatin were selectively unsilenced under cold stress, which is associated with H3K9ac accumulation and reduction of DNA methylation and H3K9me2 [39]. Cold-induced epigenetic changes result in the expression of $C O R$ genes, contributing to stress tolerance [40]. Vernalisation is the best-characterised pathway involved in cold induced epigenetic regulation [41-43]. However, our understanding of the epigenetic regulation underlying cold acclimation is limited [40].

Due to the extension of rubber cultivation to suboptimal areas, well beyond the native environment of $10^{\circ} \mathrm{N} / \mathrm{S}$ of the equator and $400 \mathrm{~m}$ above sea level, the cold tolerance of $H$. brasiliensis has been a focus of research. Several studies investigated altered physiological parameters under cold stress $[4,44,45]$, but the molecular mechanisms of cold responses in $H$. brasiliensis have not been systemically investigated. In this work, we analyse the expression profiles and DNA methylation patterns of cold- and methylation-related genes in $H$. brasiliensis clones from different geographical locations. Our results suggest that cold-induced epigenetic modifications play a more important role than genetic variation in cold acclimation of $H$. brasiliensis. 


\section{Methods}

\section{Plant materials and treatments}

Sixty-day-old seedlings of $H$. brasiliensis cultivar Reyan 7-33-97 self-rooting juvenile clones were provided by the Chinese Academy of Tropical Agriculture Sciences (Danzhou Hainan, P.R. China). The seedlings were cultivated in a growth chamber (MLR-352H-PC, Panasonic, Japan) under the control conditions: 16-h light (100 lx) /8-h dark, $75 \%$ relative humidity, at $28{ }^{\circ} \mathrm{C}$. For cold treatment, the temperature of the growth chamber was switched to $19{ }^{\circ} \mathrm{C}$ or $4{ }^{\circ} \mathrm{C}$ while the setting for lighting, photoperiod and relative humidity was kept intact. For short-term cold treatment, leaf samples were collected at $0,3,6,12$, and $24 \mathrm{~h}$ after treatment. For long-term cold treatment, the seedlings were cultivated at $19{ }^{\circ} \mathrm{C}$ for 1 month (1-CT), transferred to $28{ }^{\circ} \mathrm{C}$ for recovery for 1 month, then transferred to $19{ }^{\circ} \mathrm{C}$ for 1 month (2-CT). After recovery for 1 month, the seedlings were cultivated at $19{ }^{\circ} \mathrm{C}$ for 1 month (3-CT). After each treatment, the treated and control seedlings (cultivated at $28{ }^{\circ} \mathrm{C}$ [mock]) were photographed. Leaf samples were collected and immediately frozen, ground in liquid nitrogen, and stored at $-80{ }^{\circ} \mathrm{C}$ until RNA and DNA extraction. Five seedlings were selected for each treatment and three independent biological replicates were performed.

Leaf samples from four different geographical locations were collected from mature rubber trees in April and October 2016. Samples of cultivars Yunyan77-4, Yunyan77-2, GT1, RRIM600, and Reyan87-3 were collected from an experimental plantation of the College of Tropical Crop Science, Yunnan Agricultural University in Puer, Yunnan Province. Samples of cultivars Yunyan77-4, Yunyan77-2, Yunyan73-46, PR107, and Reyan 87-9 were collected from an experimental plantation of the Yunnan Institute of Tropical Crops in Xishuangbanna, Yunnan Province. Samples of cultivars Wenchang11, Reyan88-13, Reyan7-18-55, RRIM600, and PR107 were collected from an experimental plantation of the Wenchang Rubber Research Institute in Wenchang, Hainan Province. Samples of RRIM600, PR107, and Reyan7-18-55 were collected from Nanxin farm in Sanya, Hainan Province. The mean temperature, longitude, and latitude of the four locations are listed in Table 1. Leaf samples were collected from five individual trees of each cultivar per site, wrapped in aluminium foil and frozen in liquid nitrogen. Three independent biological replicates were performed. The samples were ground in liquid nitrogen and stored at $-80{ }^{\circ} \mathrm{C}$ until RNA and DNA extraction. Genomic DNA was isolated according to a method described previously [46]. Total RNA was extracted as described elsewhere [47].

\section{Quantitative real-time PCR (qRT-PCR)}

First-strand cDNA was synthesised using a cDNA synthesis kit according to the manufacturer's instructions (Fermentas, Vilnius, Lithuania). qRT-PCR was performed according to Wang's method [48]. The primer sets for qRT-PCR are listed in Additional file 1: Table S1. HbRH8 is used as internal control for expression profile in different tissue suggested by Li et al., [49]. HbACT7b was used as control for other qRT-PCR. Relative expression levels were calculated by the $2^{-\Delta \Delta C T}$ method. Each biological sample was performed with three independent repetitions [50]. Statistical analysis was performed by Duncan's multiple range test with SPSS software. Means were considered significantly different at values of $P<0.05$ and $<0.01$. Cluster analysis of transcriptional profiles was performed using CLUSTER software (http://bonsai.hgc.jp/ $\sim$ mdehoon/software/cluster/software.htm). The heatmap was generated by Java Treeview 4 software [51].

\section{Bioinformatics analysis of promoters}

Promoter sequences were predicted using Bioedit software (http://www.mbio.ncsu.edu/BioEdit/bioedit.html) and confirmed using BLASTP at NCBI (https://blast. ncbi.nlm.nih.gov/Blast.cgi). In silico cloning was carried out as described previously [52]. Promoter fragments (200-400 bp) were amplified by PCR using the primers in Additional file 1: Table S2. The cis-elements of the promoters were predicted by PlantCare online software (http://bioinformatics.psb.ugent.be/webtools/plantcare/ html/)(Additional file 1: Table S3) [53].

\section{Methylated CpG island screening}

Five micrograms of genomic DNA were digested by SmaI overnight to cleave unmethylated CCCGGG to generate blunt-end products, then by XmaI to cleave CCCGGG irrespective of methylation status to generate

Table 1 Locations of the rubber plantations selected for leaf sample collection

\begin{tabular}{|c|c|c|c|c|c|}
\hline \multirow[t]{2}{*}{ Location } & \multirow[t]{2}{*}{ Latitude } & \multirow[t]{2}{*}{ Longitude } & \multicolumn{3}{|c|}{ Mean temperature $^{a}$} \\
\hline & & & Annual & Summer. & Winter \\
\hline Sanya & N18¹9'58.58" & E109²7'35.35" & $25.7^{\circ} \mathrm{C}$ & $28.7^{\circ} \mathrm{C}$ & $21.4^{\circ} \mathrm{C}$ \\
\hline Wenchang & N19³7'37.29" & E110³8'37.29" & $24.4^{\circ} \mathrm{C}$ & $28.3^{\circ} \mathrm{C}$ & $19.3^{\circ} \mathrm{C}$ \\
\hline Xishuangbanna & N22º0'55.15" & E10046'13.36" & $21.8^{\circ} \mathrm{C}$ & $25.0^{\circ} \mathrm{C}$ & $16.3^{\circ} \mathrm{C}$ \\
\hline Puer & $\mathrm{N} 22^{\circ} 47^{\prime} 45.75^{\prime \prime}$ & E10058'57.72" & $19.0^{\circ} \mathrm{C}$ & $22.3^{\circ} \mathrm{C}$ & $14.0^{\circ} \mathrm{C}$ \\
\hline
\end{tabular}

${ }^{\mathrm{a}}$ Temperatures are from the China Meteorological Administration (www.cma.gov.cn) 
cohesive-end products. The 5'-CCGGTAGCTAAT GAACCAT-3' and 5'-ATCGATTACTTGGTA -3' oligonucleotides $(50 \mu \mathrm{M}$ each) were mixed and annealed at $65{ }^{\circ} \mathrm{C}$ for 5 min. A 500-ng aliquot of digested DNA was ligated with T4 ligase (TaKaRa, Dalian) at $16{ }^{\circ} \mathrm{C}$ overnight. The ligated fragments were amplified by PCR at $96{ }^{\circ} \mathrm{C}$ for $20 \mathrm{~s}, 58{ }^{\circ} \mathrm{C}$ for $25 \mathrm{~s}$, and $72{ }^{\circ} \mathrm{C}$ for $2 \mathrm{~min}$ for 30 cycles using a single adaptor-specific primer (5'ATGGTTCATTAGCTACCGGG-3'). Differential display screening was performed by amplifying DNA fragments by PCR using the initial PCR product as a template and a 10-base oligonucleotide primer. PCR products were separated on agarose gel and stained with ethidium bromide [54].

\section{Bisulphite sequencing}

Genomic DNA was isolated and subjected to bisulphite treatment using an EZ DNA Methylation-Gold kit (Zymo Research, Orange, CA, USA) according to the manufacturer's instructions. Bisulphite-treated and intact DNAs (not treated with bisulphite) were amplified by PCR using the primers in Additional file 1: Table S2. The PCR products were ligated into the pMD19-T vector (TaKaRa, Dalian) and transformed into E. coli DH5a strain for bisulphite sequencing. To check the conversion rate of EZ DNA Methylation-Gold kit, plasmid containing unmethylated DNA isolated from E. coli was treated with or without bisulphite and used as PCR template. The PCR products were further ligated into pMD19-T vector and transformed into E. coli DH5a strain. Ten clones were randomly selected for sequencing. The conversion rate of bisulfite sequencing was calculated. Threshold of the conversion rate to decide "unmethylated" was selected as $\geq 90 \%$. Methylation patterns were evaluated using CyMATE software. The sequences were aligned using MEGA.6 and ClustalW server (http://www.ch.emb net.org/software/ClustalW.html) and analysed using Cytosine Methylation Analysis Tool for Everyone (CyMATE) software (http://cymate.org/cymate.html) [55].

\section{Results}

\section{Gene expression profiles after short-term cold treatment}

To investigate cold-responsive genes of $H$. brasiliensis, 60-day-old seedlings were transferred to $19{ }^{\circ} \mathrm{C}$ or treated at $4{ }^{\circ} \mathrm{C}$ and gene expression was analysed by qRT-PCR. $H b I C E 1$ expression was induced at $3 \mathrm{~h}$, and continuously up-regulated to $12 \mathrm{~h}$, but down-regulated at $24 \mathrm{~h}$ after $19{ }^{\circ} \mathrm{C}$ treatment, whereas the expression of HbICE2 was continuously suppressed from $3 \mathrm{~h}$ to $24 \mathrm{~h}$ after treatment (Fig. 1a). In contrast, both HbICE1 and HbICE2 were upregulated after treatment at $4{ }^{\circ} \mathrm{C}$; the induction of $H b I C E 2$ was more durable and stronger than that of HbICE1 (Fig. 1b). HbCBFs expression showed a similar pattern. $H b C B F 1$ was strongly induced at $3 \mathrm{~h}$ and $6 \mathrm{~h}$ and returned to low level at $16 \mathrm{~h}$ after $19{ }^{\circ} \mathrm{C}$ treatment, whereas $\mathrm{HbCBF} 2$ and $\mathrm{HbCBF} 3$ expression was only slightly increased (Fig. 1c). When treated at $4{ }^{\circ} \mathrm{C}, \mathrm{HbCBF} 2$ and $\mathrm{HbCBF} 3$ were continuously upregulated from $3 \mathrm{~h}$ to $24 \mathrm{~h}$ after treatment, but $H b C B F 1$ was not (Fig. 1d). Additionally, $C O R$ genes (including two early response to dehydration genes [HbERD10 and HbERD14] and three $H b M Y B$ genes) were analysed. After treatment at $19{ }^{\circ} \mathrm{C}, H b E R D 14$ and $H b M Y B 15-3$ were upregulated at $24 \mathrm{~h}$ and $3 \mathrm{~h}$, respectively (Fig. 2a and c). Under $4{ }^{\circ} \mathrm{C}, H b E R D 14$ was sharply down-regulated, whereas HbERD10 showed durable upregulation and $H b M Y B 15-3$ were upregulated only at $24 \mathrm{~h}$ after treatment (Fig. $2 \mathrm{~b}$ and d). These data suggest that different members of the ICE/CBF and COR gene families responded to different levels of cold stress and showed different temporal dynamics of expression levels.

To determine whether epigenetic modification plays a role in the cold response of $H$. brasiliensis, we assessed the expression of three DNA methylation-related genes. $H b C M T$ and $H b D R M$ were induced at $3 \mathrm{~h}$ and $6 \mathrm{~h}$ after treatment at $19{ }^{\circ} \mathrm{C}$, but showed steady suppression at $4{ }^{\circ}$ C, whereas HbMET1 was continuously downregulated by $19{ }^{\circ} \mathrm{C}$ and $4{ }^{\circ} \mathrm{C}$ (Fig. 3), suggesting that DNA methylation is involved in the cold response of $H$. brasiliensis.

\section{Long-term cold treatment influences phenotype and gene expression profiles}

To investigate whether long-term cold treatment alters phenotype and the expression of COR genes, $H$. brasiliensis seedlings were treated at $19{ }^{\circ} \mathrm{C}$. Because continuous cold treatment might lead to leaf falling, the seedlings were treated at $19{ }^{\circ} \mathrm{C}$ for 1 month (1-CT), then transferred to $28{ }^{\circ} \mathrm{C}$ for recovery for 1 month, followed by treatment at $19{ }^{\circ} \mathrm{C}$ for 1 month (2-CT) or 2 months (3-CT) with a 1 month interval for recovery at $28{ }^{\circ} \mathrm{C}$. As shown in Fig. 4a, the 1-Mock, 2-Mock, and 3-Mock controls (cultivated at $28{ }^{\circ} \mathrm{C}$ ) did not show evident alteration of phenotype, whereas all cold-treated seedlings (1-CT, 2-CT, and 3-CT) showed leaf chlorosis and growth retardation. Leaf of the mock seedlings was greener than the cold treated leaf, suggesting that development or maintenance of chloroplast might be affected by low temperature. The expressionlevels of HbICE1 and HbICE2 were much higher in 1-CT than in 1-Mock, but significantly lower in 2-CT and 3-CT than in 2-Mock and 3-Mock. While HbCBF2 was rapidly induced in 1-CT, $\mathrm{HbCBF1}$ was just up-regulated in 3-CT compared with each mock control. Similar to the expression profiles of HbICEs HbMYB15-1, HbMYB15-3, and $H b E R D$ genes were upregulated in 1-CT and down regulated in 2-CT and 3-CT (Fig. 4b), whereas HbMYB15-2 was always suppressed in all 1-CT, 2-CT and 3-CT. Interestingly, all three methylation-related genes were responsive to long-term cold treatment. $H b D R M$ expression was induced after the first (1-CT) and second (2-CT) cold 

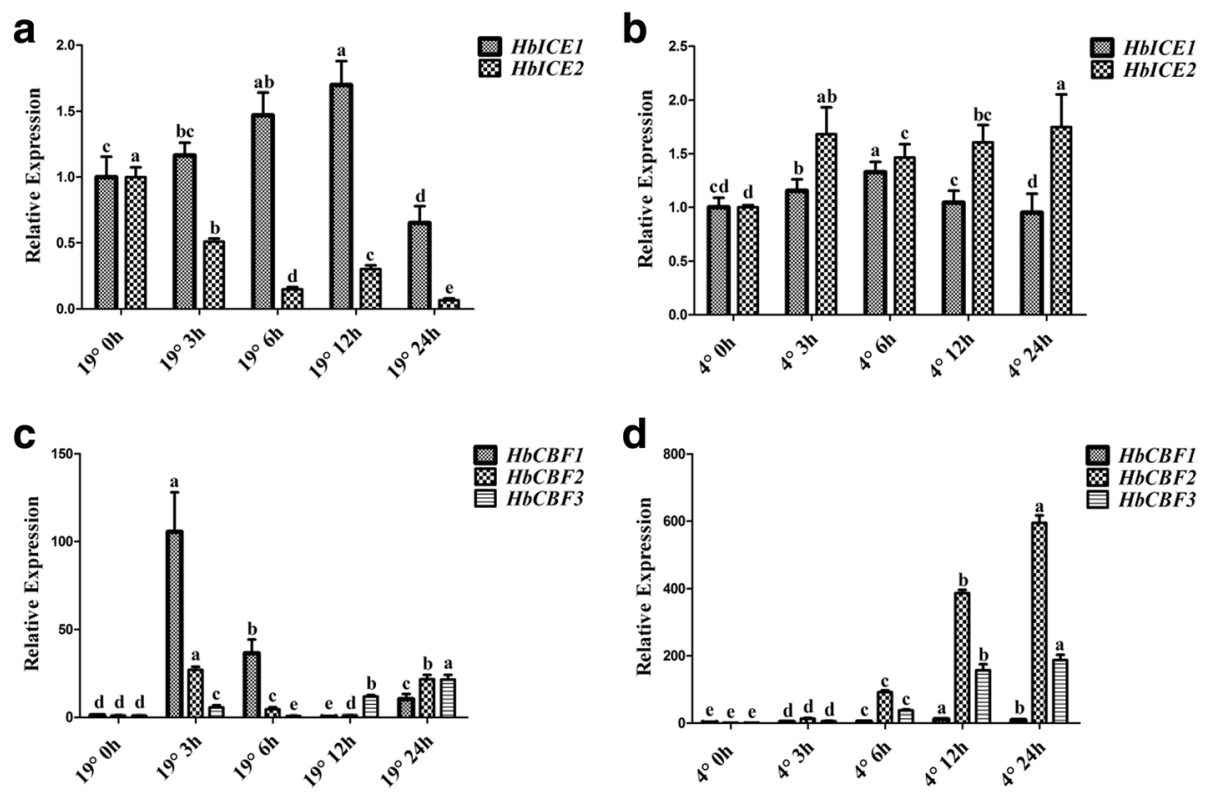

Fig. 1 Chilling treatment induced the expression of the $H b / C E$ and $H b C B F$ genes of $H$. brasiliensis. Seedlings of $H$. brasiliensis were treated at $19{ }^{\circ} \mathrm{C}$ (a and $\mathbf{c}$ ) or $4{ }^{\circ} \mathrm{C}$ (b and $\mathbf{d}$ ). Samples were collected at the time points indicated. The expression levels of Hb/CE (a and $\left.\mathbf{b}\right)$ and $H b C B F(\mathbf{c}$ and $\mathbf{d}$ ) genes were analysed by qRT-PCR. Values are presented as the mean standard error of three independent biological replicates. Different letters indicate significant differences $(P<0.05)$ according to one-way analysis of variance

treatments, but returned to normal after the third cold treatment (3-CT), while HbMET and HbCMT expression did not increase until the third cold treatment (3-CT) (Fig. 4c), suggesting that long-term cold treatment might alter DNA methylation status in $H$. brasiliensis.
Long-term cold treatment altered DNA methylation patterns To determine whether long-term cold treatment altered the genome-wide DNA methylation status, we performed methylated CpG island screening. Genomic DNA was digested with SmaI followed by XmaI. The DNA fragments

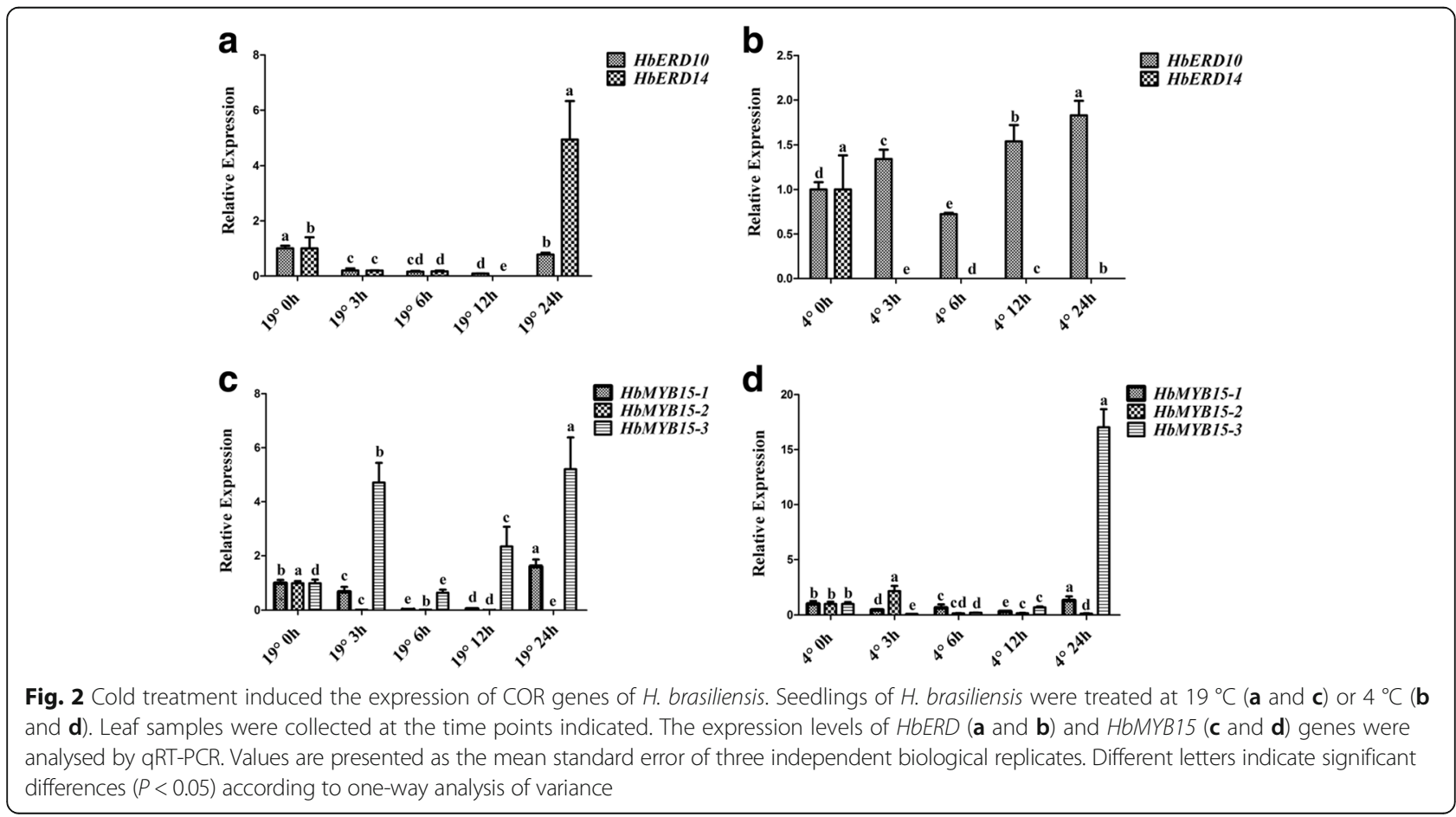



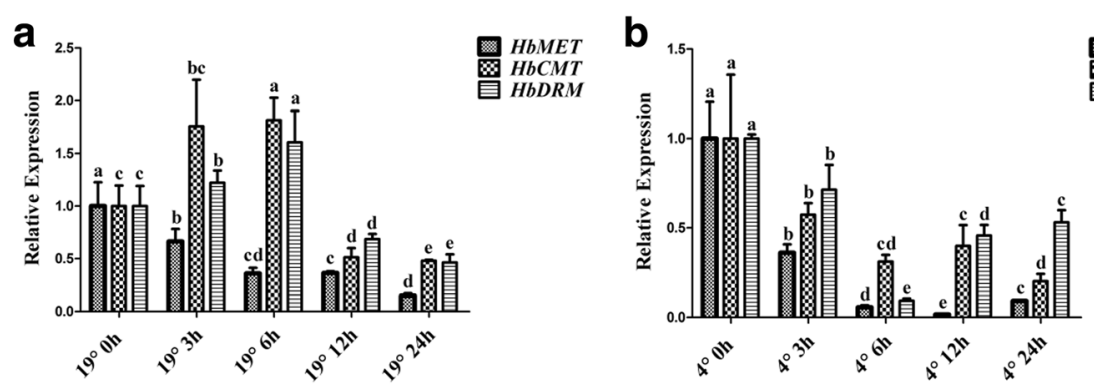

Fig. 3 Cold treatment altered the expression levels of DNA methylation related genes in $\mathrm{H}$. brasiliensis. Seedlings of $\mathrm{H}$. brasiliensis were treated at $19^{\circ} \mathrm{C}(\mathbf{a})$ or $4{ }^{\circ} \mathrm{C}$ (b). Leaf samples were collected at the time points indicated. The expression levels of HbMET, HbCMT, and HbDRM were analysed by qRT-PCR. Values are presented as the mean standard error of three independent biological replicates. Different letters indicate significant differences $(P<0.05)$ according to one-way analysis of variance

were ligated with the adapter sequence and amplified by PCR. The PCR band profiles of the 1-Mock, 2-Mock, and 3-Mock samples were similar. However, the 1-CT, 2-CT, and 3-CT samples showed different band profiles (Additional file 1: Figure S1), suggesting that cold treatment induced significant alteration of the DNA methylation status of CpG islands throughout the genome.

To determine whether long-term cold treatment altered the DNA methylation pattern of COR and methylation-related genes, the promoter sequences of $H b I C E 1$, $H b C B F 2$, and $H b M E T$ were bisulphite-sequenced. Conversion rates of plasmid DNA of $H b I C E 1, H b C B F 2$, and $H b M E T$ promoters using EZ DNA Methylation-Gold kit were 95.51\%, 91.41\% and $96.36 \%$, respectively (Additional file 1: Figure S2), suggesting that the unmethylated cytosine could be efficiently conversed by the kit. $90 \%$ of the conversion rate was selected as a threshold to decide methylated or not methylated in the following study. The 324-bp sequence of the HbICE1 promoter contained cis-regulatory elements such as ARE, CATT-motif, CAAT-box, CCAAT-box, CGTCA and TGACGpalindrome motif, MBS, TATA-box, and several unnamed motifs (Additional file 1: Table S3). In total, 51 CpG islands were present in the examined fragment, including 2 CGN, 27 CHG, and $21 \mathrm{CHH}$ methylation sites. In the 1Mock, 2-Mock, and 3-Mock control samples, few methylation sites in the HbICE1 promoter were altered. After the second cold treatment (2-CT), 24 CHG (88.9\%) and $19 \mathrm{CHH}$ (90.5\%) methylation sites were demethylated (termed THG and THH, respectively), suggesting that long-term cold treatment caused universal demethylation of the HbICE1 promoter (Fig. 5a). Notably, the CHG methylation site at the MBS (MYB binding site) cis-element was demethylated in the 2-CT sample (Additional file 1: Figure S3A), suggesting that demethylation of the ciselement alters the binding capacity and transcriptional activity of MYB. Surprisingly, almost all of the demethylated sites in 2-CT were switched to methylation in the 3-CT sample (Fig. 5a).
A similar pattern was observed in the $H b C B F 2$ promoter. The 318-bp $H b C B F 2$ promoter region contained cis-elements such as ABRE, ARE, CAAT, CAT, G-boxes, HSE, and TATA-boxes (Additional file 1: Table S3). The numbers of CGN, CHG, and $\mathrm{CHH}$ methylation sites were 8,11 , and 54, respectively. In the 1-Mock, 2-Mock, and 3Mock control samples, no methylation sites underwent demethylation. Few demethylation sites were observed in the 1-CT sample (Fig. 5b). However, 48 THH (88.9\%), 7 TGN (87.5\%), and 11 THG (100\%) demethylation sites were detected in the 2-CT sample. Many demethylation sites were located in TATA and ABRE boxes, allowing RNA polymerase and ABRE-binding transcription factors to bind the promoter and regulate the transcription of $H b C B F 1$ (Additional file 1: Figure S3B). As observed for $H b I C E 1$, most demethylation sites returned to a hypermethylation status after 3-CT (Fig. 5b).

The 287-bp fragment of the HbMET promoter contained many cis-elements; e.g. AT, CAAT-boxes, ERE, GARE, HSE, and P-boxes (Additional file 1: Table S3). The promoter sequence contained 44 methylation sites, including $3 \mathrm{CGN}, 5 \mathrm{CHG}$, and $36 \mathrm{CHH}$ sites. After the first cold treatment (1-CT), almost all methylation sites were demethylated, including 3 TGN (100\%), 5 THG (100\%), and $35 \mathrm{THH}$ (97.2\%) sites, whereas the methylation pattern of the 1-Mock, 2-Mock, and 3-Mock control samples was relatively unchanged. The hypomethylation status was maintained in the 2-CT and 3-CT samples (Fig. 5c), indicating that cold induced hypomethylation status of the $H b M E T$ promoter is more sustainable to cold treatment.

Cold stress induced promoter hypomethylation and increased the expression of DNA methylation-associated genes, such as HbMET (Figs. 4 and 5). How can the increased DNA methyltransferase transcription and low promoter DNA methylation levels induced by cold treatment be explained? As described above, active removal of cytosine methylation is catalysed by DME, ROS, and DML, members of the DNA glycosylase family $[27,34,35,40]$. In 


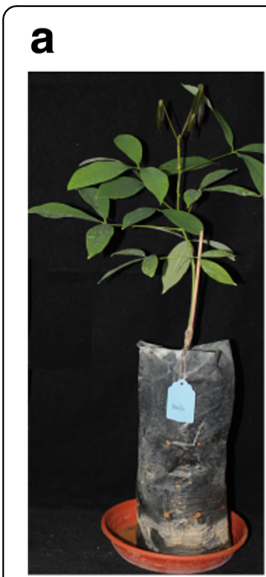

1-Mock

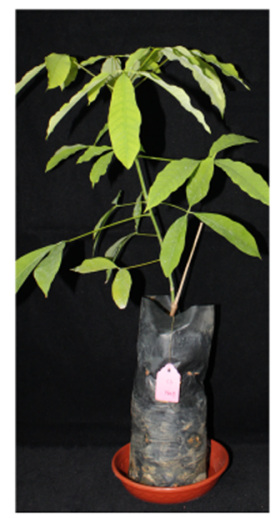

1-CT

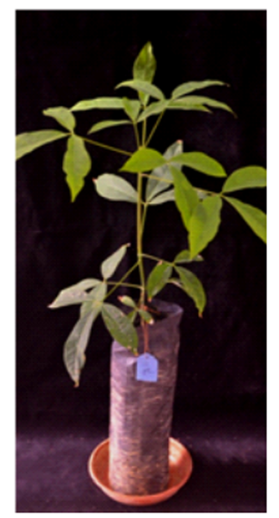

2-Mock

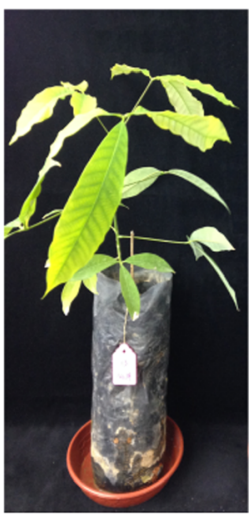

2-CT

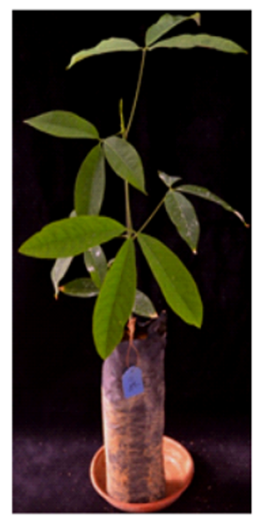

3-Mock

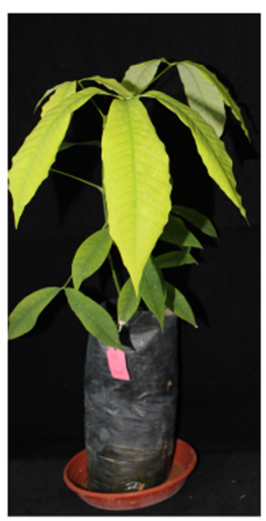

3- CT

b
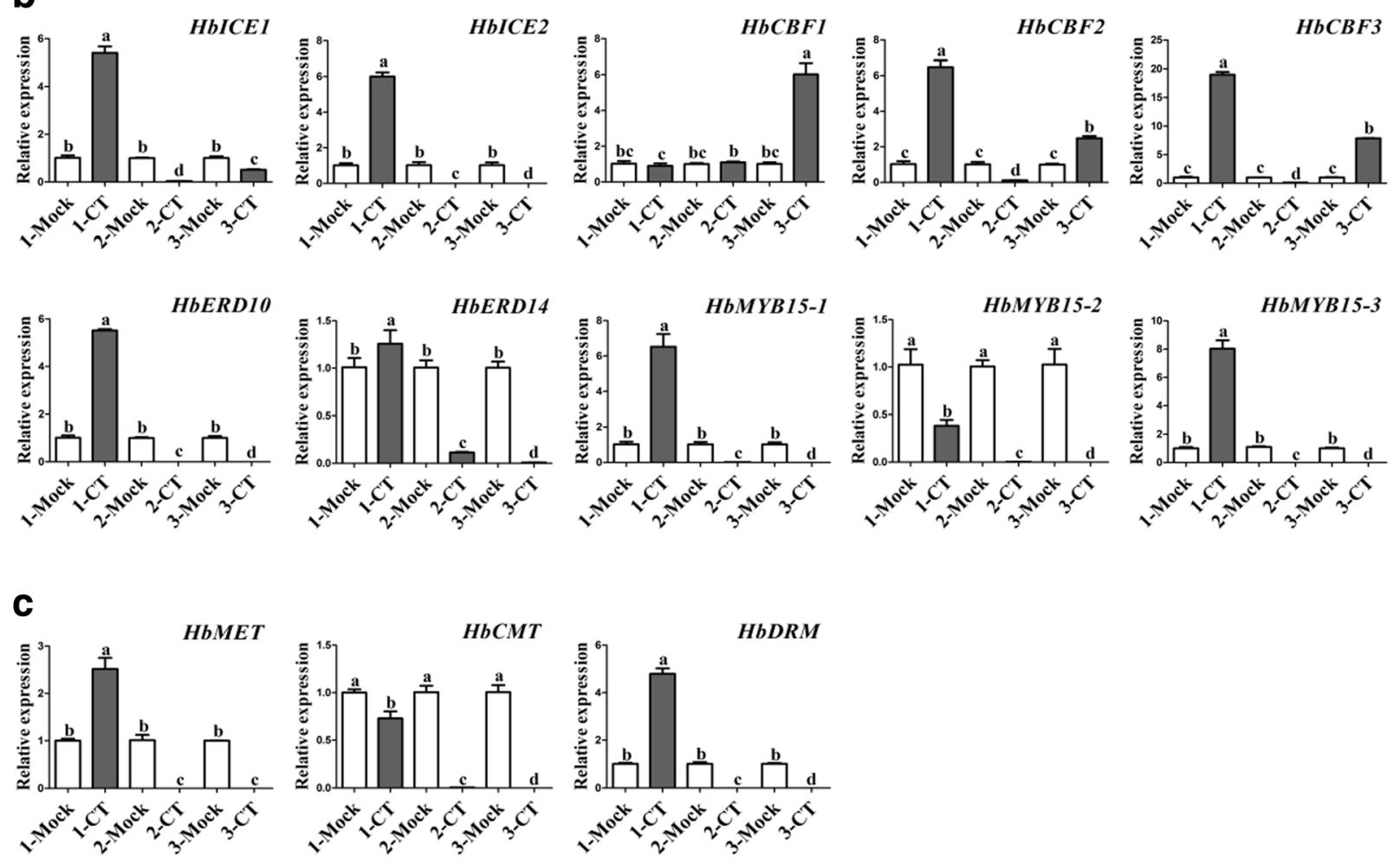

Fig. 4 Effect of long-term cold treatment on phenotype and gene expression patterns. Seedlings of $\mathrm{H}$. brasiliensis were treated at $19^{\circ} \mathrm{C}$ for 1 month (1-CT), transferred to $28^{\circ} \mathrm{C}$ for recovery for 1 month, then treated at $19^{\circ} \mathrm{C}$ for 1 month $(2-\mathrm{CT})$. After recovery for 1 month, the seedlings were again cold-treated for 1 month (3-CT). After each treatment, the phenotypes were photographed (a) and leaf samples were collected. The expression levels of cold-related genes $(\mathbf{b})$ and methylation-related genes $(\mathbf{c})$ were analysed by qRT-PCR. Values are presented as the mean standard error of three independent biological replicates. Different letters indicate significant differences $(P<0.05)$ according to one-way analysis of variance

silico cloning identified $12 \mathrm{HbDME}, 2 \mathrm{HbROS}$, and 7 $H b D M L$ genes in the $H$. brasiliensis genome. qRT-PCR showed that these demethylation-associated genes, with the exception of $H b D M L 3$ and $H b D M L 7$, were strongly induced by long-term cold treatment (Fig. 6). However, bisulphite sequencing revealed that none of these genes' promoters were demethylated after longterm cold treatment (Additional file 1: Figure S4).
These results suggest that cold induced the transcription, but did not alter the demethylation status of demethylation-associated genes.

\section{Methylation status of HbICE1 and HbMET promoters} according to geographical location and season To investigate whether hypomethylation of HbICE1 and $H b M E T$ could be induced by natural environmental 


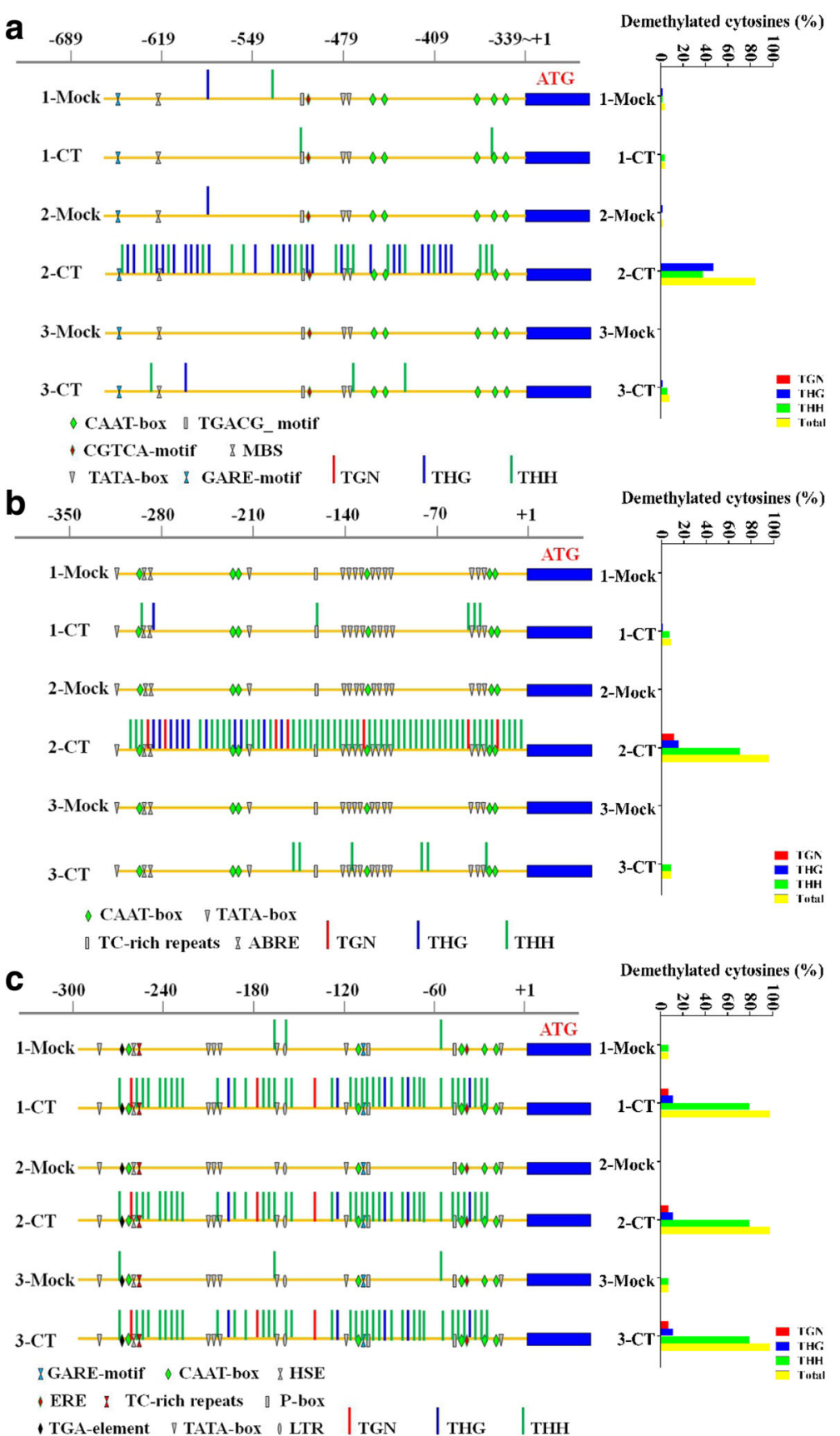

Fig. 5 Long-term cold treatment induced demethylation of promoters. Seedlings of $\mathrm{H}$. brasiliensis were treated at $19^{\circ} \mathrm{C}$ for $1 \mathrm{month}(1-\mathrm{CT})$, transferred to $28^{\circ} \mathrm{C}$ for recovery for 1 month, and then treated at $19^{\circ} \mathrm{C}$ for 1 month $(2-\mathrm{CT})$. After recovery for 1 month, the seedlings were again cold-treated for 1 month (3-CT). Leaf samples were collected after each treatment. Total DNA was isolated and treated with or without bisulphite. Methylation patterns were evaluated using CyMATE software. Probable TGN, THG, and THH demethylation sites were identified by the software and projected symbolically. The percent of each demethylation type were indicated at the right side. (a) A 324-bp region of the HICE1 promoter. (b) A 318-bp region of the HbCBF2 promoter. (c) A 287-bp fragment of the HbMET promoter

conditions, we selected four rubber plantation locations-Sanya (N18 $19^{\prime} 58.58^{\prime \prime} ;$ E109 $\left.27^{\prime} 35.35^{\prime \prime}\right)$ and

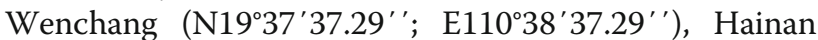
Province; and Xishuangbanna (N22 $00^{\prime} 55.15^{\prime \prime}$; E100 $46^{\prime}$ $\left.13.36^{\prime \prime}\right)$ and Puer (N22 $47^{\prime} 45.75^{\prime \prime}$; E100 $\left.58^{\prime} 57.72^{\prime \prime}\right)$,
Yunnan Province. The four locations have mean temperatures ranging from 14.0 to $21.4{ }^{\circ} \mathrm{C}$ in winter and from 22.3 to $28.7^{\circ} \mathrm{C}$ in summer (Table 1). Leaf samples of six cultivars from Puer, five cultivars from Xishuangbanna, four cultivars from Wenchang, and three cultivars from 

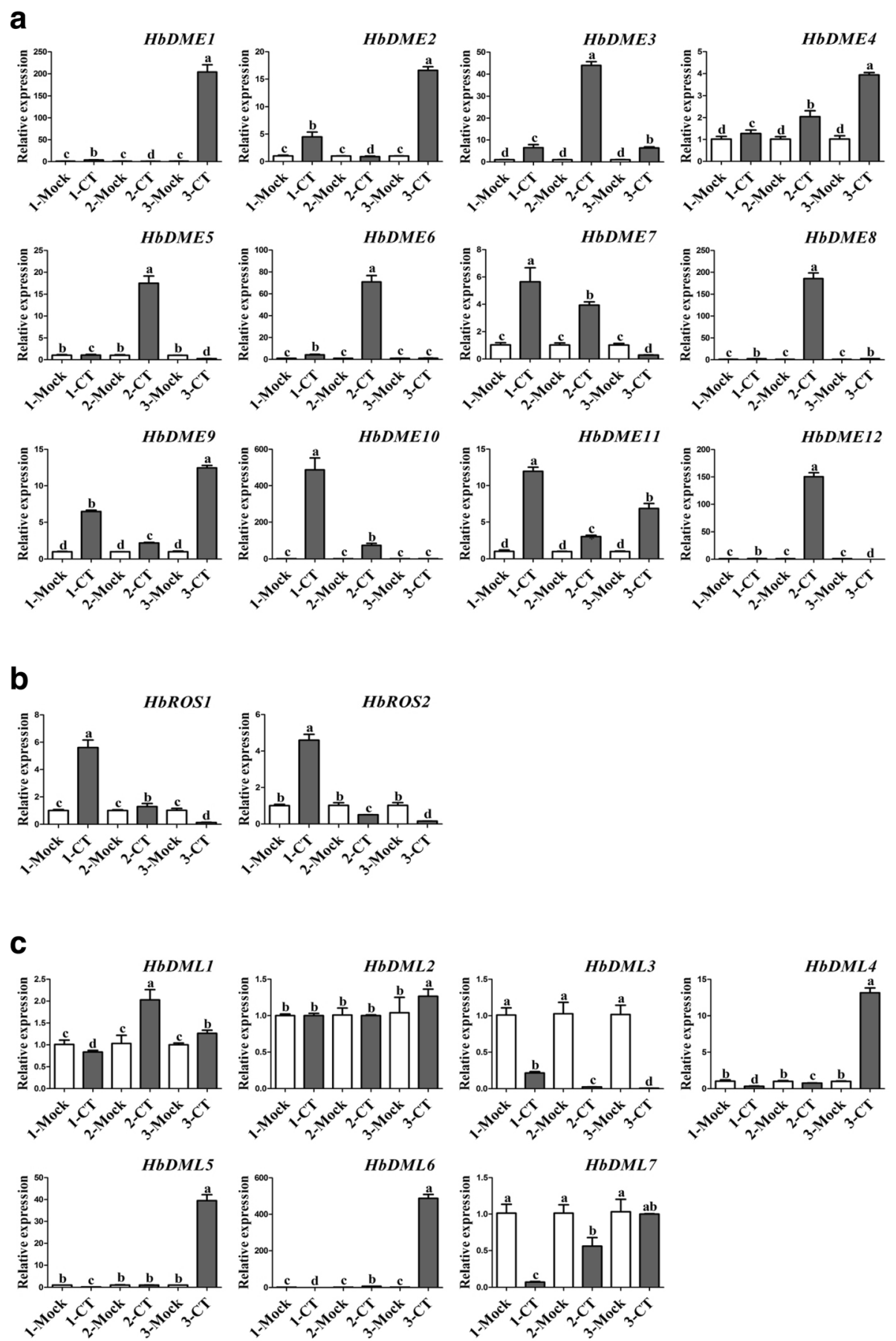

Fig. 6 Long-term cold treatment regulated the expression of demethylation-related genes. Seedlings of $\mathrm{H}$. brasiliensis were treated at $19{ }^{\circ} \mathrm{C}$ for 1 month (1-CT), transferred to $28^{\circ} \mathrm{C}$ for recovery for 1 month, and then treated at $19^{\circ} \mathrm{C}$ for 1 month (2-CT). After recovery for 1 month, the seedlings were again cold-treated for 1 month (3-CT). After each treatment, leaf samples were collected for qRT-PCR. (a) HbDME, (b) HbROS, and (c) HbDML genes. Values are presented as the mean standard error of three independent biological replicates. Different letters indicate significant differences $(P<0.05)$ according to one-way analysis of variance

Sanya were collected from mature rubber trees in April and October 2016. Total DNA was isolated and treated with or without bisulphite. The promoter sequences of $H b M E T$ and HbICE1 were amplified by PCR and sequenced.
Methylation patterns were evaluated using CyMATE software.

Among 18 samples of 12 cultivars collected from the four locations, only PR107 had a single nucleotide polymorphism 
(SNP) in the 324-bp region of the HbICE1 promoter; 14 samples (77.8\%) collected in April showed evident hypomethylation in the analysed region of the HbICE1 promoter (Fig. 7a). The demethylation patterns (number, type, and position) were almost identical to those in the long-term cold-treated sample (2-CT) in chamber condition (Fig. 5a), suggesting that demethylation is induced by low temperature. Interestingly, among the four samples that did not show hypomethylation, three (RRIM600, PR107, and Reyan 7-88-5) were collected from Sanya, the most southern city in China with the highest winter temperature (Fig. 7a). This DNA demethylation was not dependent on cultivar, because the cultivars collected in Sanya (RRIM600, PR107, and Reyan 7-88-5), were also collected in other locations, confirming that environmental temperature plays a key role in regulation of demethylation of the HbICE1 promoter in the rubber tree. Another exception was the cultivar GT1, collected in Puer, the northernmost rubber plantation location in China, which showed hypermethylation of the HbICE1 promoter, suggesting that other environmental factors might also influence epigenetic modification of the HbICE1 promoter (Fig. 7a).

The HbICE1 promoters of 15 samples (83.3\%) collected in October, when rubber trees had undergone summer acclimation for several months, switched to a hypermethylation status (Fig. 7b). There was no correlation between methylation pattern and genotype. This confirmed that environmental temperature plays an important role in regulation of methylation of the HbICE1 promoter. However, there were exceptions; e.g. two samples collected from Puer (Yunyan77-4 and Reyan77-2) and one sample collected in Wenchang (Wenchang 11), which retained a hypomethylation status (Fig. 7b), suggesting that environmental factors other than temperature affect the methylation status of the HbICE1 promoter.

A similar switch in methylation status was observed in the 287-bp fragment of the $H b M E T$ promoter. Among 18 samples of 12 cultivars, no SNP was found in the 287-bp region of the HbMET promoter. As expected, most samples collected in April after winter cold acclimation showed strong hypomethylation (Fig. 8a). Furthermore, the demethylation patterns (number, type, and position) were identical to those in long-term cold-treated samples in chamber condition (Fig. 5c). Unexpectedly, the HbMET promoter was hypermethylated in three cultivars collected from Wenchang, Hainan Province in winter, and so was affected by unknown environmental factors (Fig. 8a). As expected, the $H b M E T$ promoter of almost all samples (88.9\%) collected in October switched to a hypermethylation status after summer acclimation (Fig. 8b).

\section{Gene expression patterns according to geographical location and season}

To investigate the effects of geographical location and season on the expression and methylation status of $C O R$ methylation-related genes, we subjected the HbICE1, HbICE2, HbCBF1, HbCBF2, HbCBF3, HbERD10, HbERD14, HbMYB15-1, HbMYB15-2, HbMYB15-3, $H b M E T, H b C M T$, and $H b D R M$ genes to qRT-PCR analysis. $H b A C T 7 b$ was used as controls. Cluster analysis of transcriptional profiles was performed using CLUSTER [56], and a heatmap was generated by Java Treeview 4 [51]. Although these genes are regulated by short- or long-term cold treatment (Figs. 1, 2, 3, and 4), they did not specifically respond to temperature; therefore, other biotic/abiotic factors might alter their expression. The expression of several of these genes, such as HbMYB152, $H b C B F 1, H b E R D 14$, and $H b C M T$, was significantly higher in the samples collected in April (Fig. 9a) than in October (Fig. 9b). This indicates a correlation between low temperature and expression of COR genes. No correlation with cultivar was observed (Fig. 9).

\section{Discussion}

As a perennial tropical plant, $H$. brasiliensis is native to the Amazonian forests of Brazil. Because the cultivated clones were derived from a few original 'Wickham base' seedlings, they represent only a small part of the germplasm. The limited genetic variation of the current cultivars is insufficient to carry out breeding for genetic improvements in rubber production or biotic/abiotic tolerance. The vegetative model of propagation has further narrowed the genetic base. This hypothesis was supported by genome sequencing results. Few SNPs were observed among cultivars Reyan7-33-97, RRIM600, PR107, Wenchang11, Yunyan77-4, and Reyan8-79. The density of SNPs among all cultivars averages 2 per kilobase, and 95.1-95.6\% occurred in non-coding regions. Furthermore, extremely low SNP regions ( $<1$ SNP kb), termed as 'SNP deserts', accounted for $42 \%$ of the Hevea genome [57], which is significantly higher than that reported in rice (8\%) [58] or date palm (18\%) [59]. However, different cultivars exhibit specific adaptation in their plantation areas. A number of clones, such as PB260, PR107, IRCA317, PB217, RRIM600, GT1, and Yunyan77-4, reportedly show different levels of cold tolerance [44, 45]. The successful extension of rubber tree cultivation to high latitudes is believed to benefit from long-term selective breeding of cold-resistant rubber tree clones $[2,60]$. One puzzling incongruity is the remarkable divergence in quantitative and qualitative characters amongst the popular cultivars despite their similar genetic make-up. Furthermore, the long juvenile stage limits selective breeding. We therefore proposed that epigenetic modification might be responsible for the different characters of the cultivated clones. 

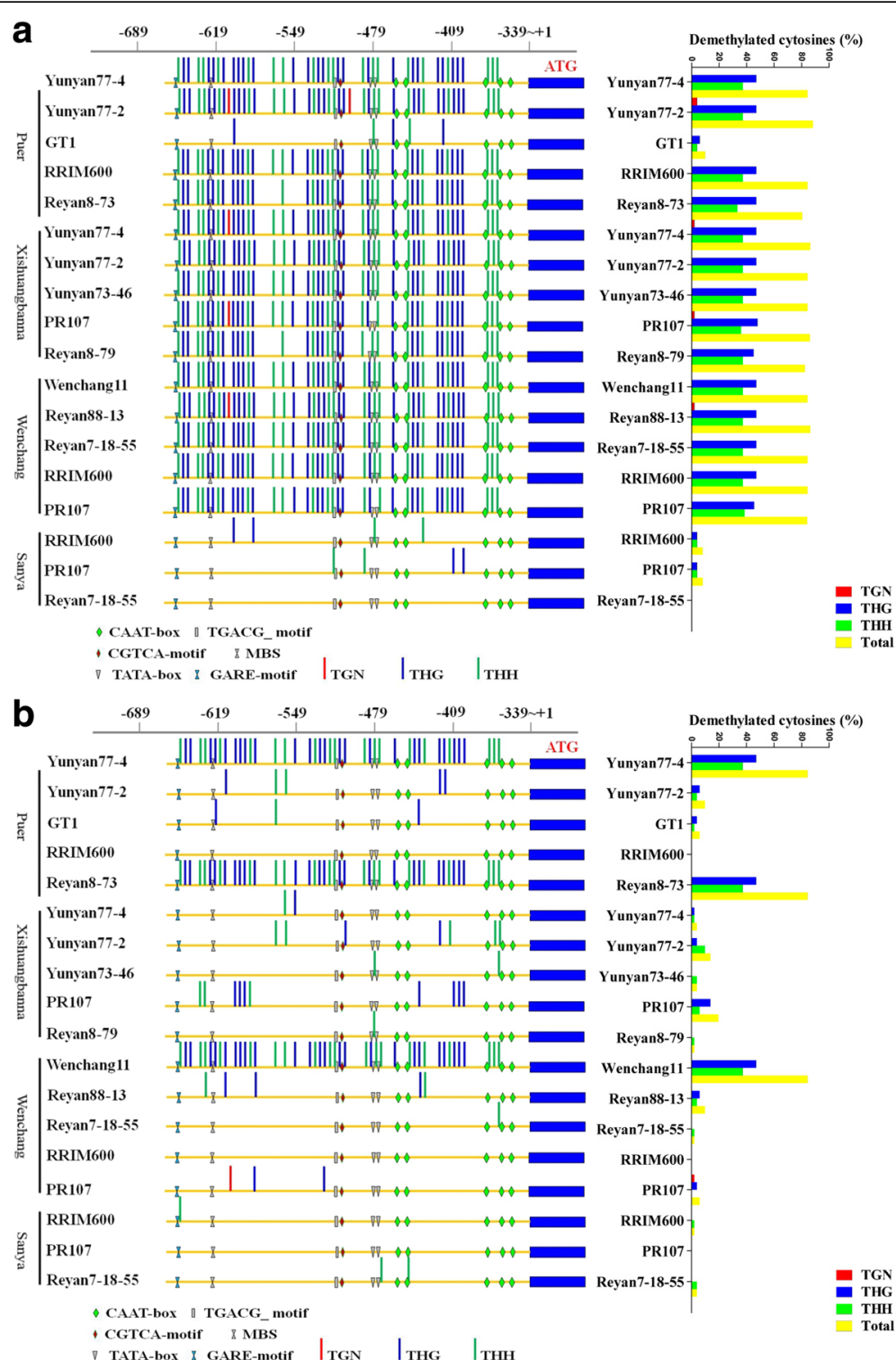

Fig. 7 Effects of season and geographical location on the methylation status of HblCE1 promoters. Leaves of six cultivars from Puer and five cultivars from Xishuangbanna, Yunnan Province; and from four cultivars from Wenchang and three cultivars from Sanya, Hainan Province were collected in April (a) and October (b). Total DNA was isolated and treated with or without bisulphite. The promoter sequence of Hb/CE1 was amplified by PCR and sequenced. The methylation pattern was evaluated by CyMATE software. The percent of each demethylation type were indicated at the right side

The dominant stress on rubber trees cultivated in high-altitude areas is low temperature. Under stress conditions, survival strategies of seed plants include gene mutation [61], genome recombination [62], and epigenetic modification [63]. However, the survival strategies of vegetatively propagated rubber tree populations are limited. Uthup et al. first reported site-specific epigenetic modification induced by environmental factors in rubber trees [64]. However, how and which factors affect acclimation of the rubber tree to unfavourable conditions is unclear. In this work, we showed that cold treatment regulated the expression of $H b C B F s$ and $H b I C E s$ genes (Fig. 1), which are involved in controlling the expression of COR genes to cope with cold stress (Fig. 2), as in Arabidopsis [33]. The differential expression patterns of $H b I C E 1$ and $H b I C E 2$, and among three $H b C B F$ genes, at $19{ }^{\circ} \mathrm{C}$ and $4{ }^{\circ} \mathrm{C}$ (Fig. 1), suggest that these homologous genes play different roles in the response to low temperature. Interestingly, cold treatment altered the expression patterns of DNA-methylation associated genes, such as HbMET, HbCMT, and HbDRM (Fig. 3), indicating that epigenetic DNA modifications are involved in 

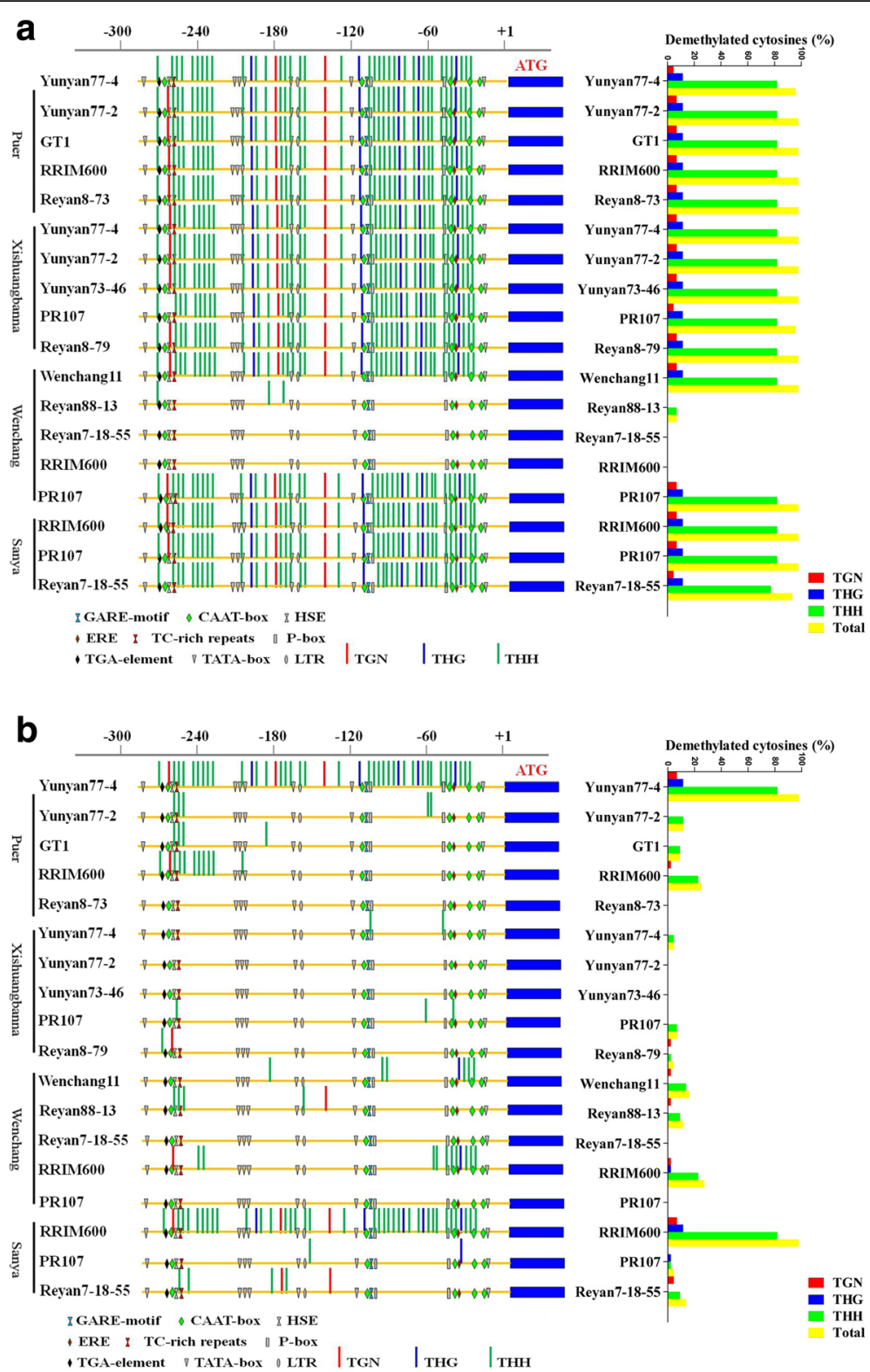

Fig. 8 Effects of season and geographical location on the methylation status of HbMET promoters. Leaves of six cultivars from Puer and five cultivars from Xishuangbanna, Yunnan Province; and from four cultivars from Wenchang and three cultivars from Sanya, Hainan Province were collected in April (a) and October (b). Total DNA was isolated and treated with or without bisulphite. The promoter sequence of HbMET was amplified by PCR and sequenced. The methylation pattern was evaluated using CyMATE software. The percent of each demethylation type were indicated at the right side

cold acclimation in $H$. brasiliensis. Thus, $H$. brasiliensis seedlings were transferred to long-term cold treatment, and methylated $\mathrm{CPG}$ island screening showed different epigenetic modifications between control and cold-treated samples (Additional file 1: Figure S1). Bisulphite sequencing confirmed that the HbICE1, HbCBF2, and HbMET promoters became hypomethylated (Fig. 5), which is in agreement with induction of gene expression (Fig. 4). Many demethylation sites occurred at cis acting elements recognized by cold related transcriptional factors, for example, the MBS (MYB binding site) cis-element in HbICE1 promoter (Additional file 1: Figure S3A). Cold treatment induced hypomethylation of retrotransposon areas of the genome of tobacco [65]. Our findings reveal that cold treatment induced hypomethylation of ICE-CBF promoter regions in $H$. brasiliensis, which is directly associated with acquisition of cold tolerance.

Other evidence that epigenetic modification is involved in cold acclimation of $H$. brasiliensis was identification of conversion of hypermethylation to hypomethylation of the 


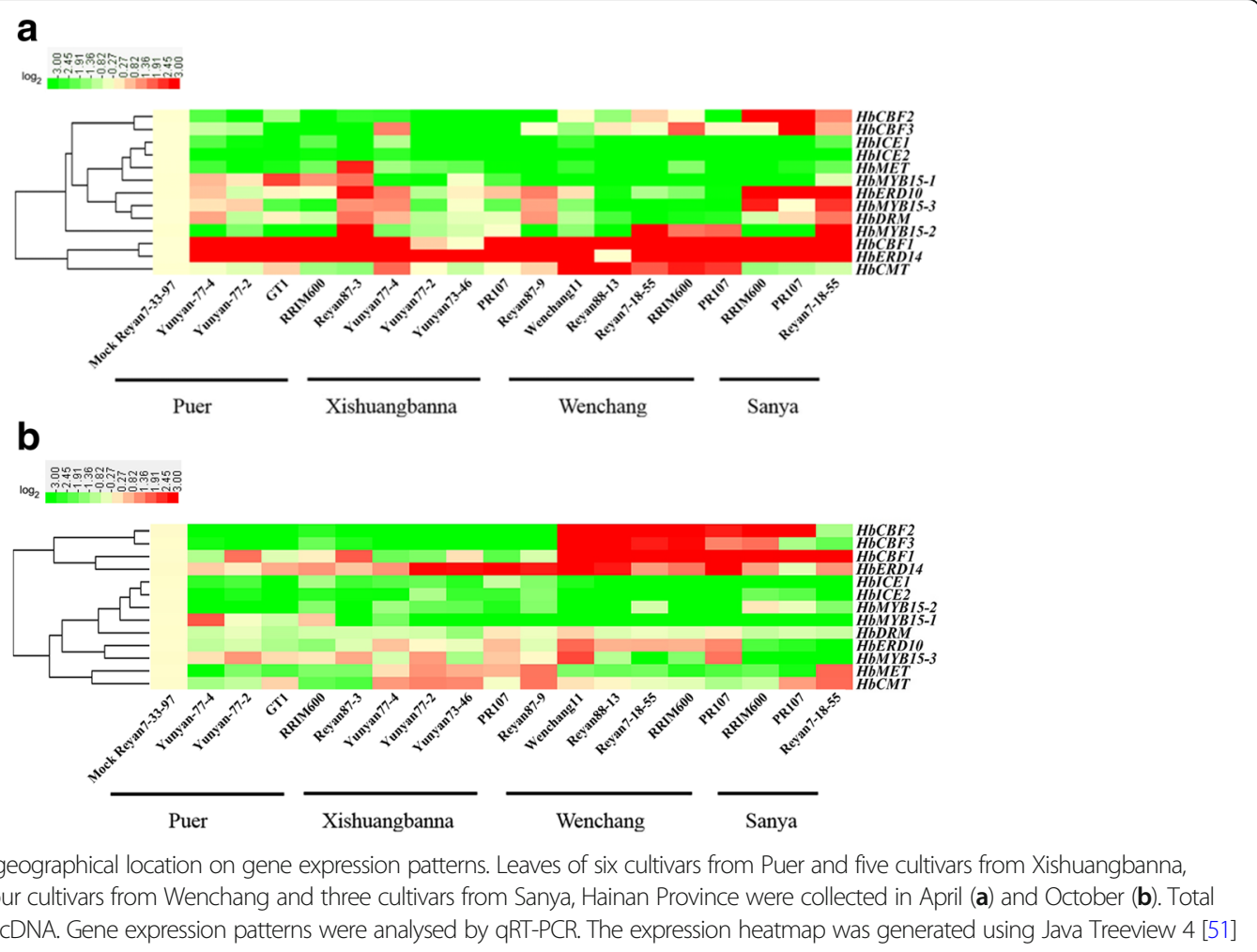

HbMET promoter by long-term cold treatment (Fig. 5c). However, MET mediates establishment and maintenance of cytosine methylation. Why did cold stress induce $H b M E T$ transcription and hypomethylation in the promoters of $H b I C E 1, H b C B F 2$, and $H b M E T$ ? To resolve this issue, we analysed the expression of genes associated with removal of cytosine methylation. In total, $12 \mathrm{HbDMEs}, 2$ HbROSs, and $7 \mathrm{HbDMLs}$ genes in the H. brasiliensis genome were identified by an in silico procedure. Among 19 demethylation-associated genes, 17 were strongly induced by long-term cold treatment (Fig. 6). Therefore, cold treatment induced hypomethylation was reasonable, although how the demethylation-associated genes and HbMET function synergistically to recognise and modify their target genes is unclear. Additionally, bisulphite sequencing revealed that no conversion of methylation status occurred in the promoters of demethylation-associated genes after cold treatment (Additional file 1: Figure S4), indicating that initiation of the transcription but not the demethylation of the demethylation-associated genes is a prerequisite for DNA demethylation.

We further investigated whether cold-induced DNA demethylation plays a role in the cold acclimation of rubber trees in a natural environment. Rubber plantations in four locations were selected, including the southernmost and northernmost rubber plantation sites in China (Table 1). Samples were collected in April and in October, respectively. Although different cultivars were planted in the four locations, the cultivars collected overlapped. Although methylation status is regulated by multiple environmental factors, the demethylation of CpG islands in the HbICE1 promoter was highly correlated with low temperature. Of the samples collected in April, 77.8\% showed hypomethylation (Fig. 7). Of the four samples that were not hypomethylated, three were collected from Sanya, which has a relatively high winter temperature (Table 1). The demethylation patterns (number, type, and position) were almost identical, as was the case in samples subjected to cold treatment in chamber (Fig. 5a). After summer acclimation, hypomethylation was switched to hypermethylation, suggesting that DNA demethylation is caused by low temperature, not other environmental factors. A similar pattern was observed in the HbMET promoter. The $H b M E T$ promoter was hypomethylated in most samples collected in April but hypermethylated in October (Fig. 8), suggesting that the hypomethylation status of $H b M E T$ target genes is maintained until April, although which genes are targets of $H b M E T$ is unknown. Although COR genes are regulated not only by cold but also by a number of biotic and abiotic stresses, the number of COR genes expressed at a high level was greater in samples collected in April than in October, indicating a correlation between low temperature and COR gene expression (Fig. 9).

Notably, although the HbICE1 and $H b M E T$ promoters were hypomethylated in most samples subjected to cold stress, there were several exceptions. For example, three 
samples collected in Wenchang in April showed hypermethylation and one sample (RRIM600) collected in Sanya showed hypomethylation of the $H b M E T$ promoter in October (Fig. 8). Similar exceptions were observed in the HbICE1 promoter (Fig. 7). As we know, neither $H b M E T$ nor $H b I C E 1$ are specifically responsive to cold stress and their expressions could be affected by multiple biotic/abiotic environmental factors such as temperature, salt, light, and osmotic stress. Each sample collected from different locations represents an individual stress combination of different environmental factors. The epigenetic modifications, e.g. DNA methylation status in $H b M E T$ and HbICE1, are coordinated by these factors. Although a common factor was cold stress for all samples, it is not difficult to understand the exceptions observed in this work, which representing different stress combinations.

Besides the temperature, altitude (height above sea level) is a major difference among Sanya, Wenchang, Xishuangbanna, and Puer. Different altitudes mean different environmental conditions, including temperature, light density, humidity, and so on, among which temperature might play a much more important role in limiting expansion of rubber tree to suboptimal area. In order to rule out the effects of other factors, rubber samples were corrected in different seasons, besides different latitudes, the switch of methylation status showed a close correlation with temperature (Figs. 7 and 8). Cold treatment induced the expression of many cold responsive genes and DNA methylation-related genes such as HbICE1, HbCBF2, HbMET, and HbDME genes. The induction of gene expression was closely correlated with cold-induced DNA demethylation in promoter. This correlation was also observed in 19 samples of 12 different cultivars collected from different geographical locations and in different seasons, and little genetic diversity was observed among these samples, reflecting the fact that low environmental temperature-induced epigenetic modifications (e.g. DNA demethylation) might play an important role in cold acclimation of $H$. brasiliensis. The alteration of genomic methylation status was prevalently documented under abiotic stresses [66-68], but cold induced DNA demethylation was not widely reported. In contrast to rubber tree that was introduced in China, crofton weed (Ageratina adenophora) is a highly invasive alien plant that is continuously spreading across subtropical areas in China through cold tolerance evolution. Recent report showed that demethylation-upregulated transcription level of CBF pathway is responsible for this evolution [69]. Results shown in this work confirmed that cold induced demethylation-upregulated transcription of ICE-CBF might also play a key role in cold acclimation in rubber tree. Recent report revealed that ROS1 promoter functions like a thermostat (i.e., methylstat) to sense DNA methylation levels and regulates DNA methylation by controlling ROS1 expression [70]. Whether rubber tree shares such a mechanism requires further investigation.

\section{Conclusions}

Cold treatment not only induced the expression of coldrelated genes and DNA-methylation related genes such as $H b I C E 1, H b C B F 2$, and $H b M E T$, but also induced the DNA demethylation in their promoters. Cold treatment increased the transcriptional activities of demethylationrelated genes ( $H b D M E, H b R O S$, and $H b D M L)$, but did not alter the promoter methylation status. The DNA methylation status of the HbICE1 and HbMET promoters was closely related with the environmental temperature. Hypomethylation of HbICE1 and HbMET promoters induced by cold was highly correlated with the expression level of COR genes, but not with the genetic backgrounds of cultivars. Little genetic diversity was observed in the HbICE1 and HbMET promoters in different cultivars. It could be proposed that cold-induced epigenetic modification is more important than genetic variation in cold tolerance of different hevea cultivars.

\section{Additional file}

\begin{abstract}
Additional file 1: Figure S1. Methylated CpG island screening. Figure S2. Conversion rate of bisulfite sequencing. Figure S3. Representative Sanger sequencing chromatograms of the bisulphite-treated DNA samples of long-term cold treatment. Figure S4. Graphical representation of methylation patterns of three gene promoters altered by long-term cold treatment. Table S1. List of the primers for Quantitative real-time PCR. Table S2. List of the primers for PCR amplification of genes promoters. Table S3. Cis-elements existing in promoters of pHbICE1, pHbCBF2 and pHbMET. (DOCX $1845 \mathrm{~kb})$
\end{abstract}

\section{Abbreviations}

CBFs: C-repeat-binding factors; CMT: chromomethylase; COR: cold-responsive; CRT/DRE: C-repeat/dehydration response elements; CT: cold treatment; DME: Demeter; DML: demeter-like; DNMT: DNA methyltransferase;

DREB: dehydration-responsive element-binding factor; DRM: domains rearranged methyltransferase; HOS: high expression of osmotically responsive genes; ICE: Inducer of CBF expression; MET: methyltransferase; RDM: RNAdirected DNA methylation; ROS: repressor of silencing; SAM: S-adenosyl-Lmethionine

\section{Acknowledgments}

We would like to thank the reviewers and editors for their careful reading and helpful comments on this manuscript.

\section{Funding}

This work was supported by the National Natural Science Foundation of China (grant numbers 31370608 and 31560197).

\section{Availability of data and materials}

The datasets used and/or analysed during the current study available from the corresponding author on reasonable request.

\section{Authors' contributions}

XT performed most of the experiments; QW performed the bioinformatics analysis; HY cloned the COR and methylation-related genes; XH supervised and wrote the manuscript. All authors have read and approved the final version of the manuscript. 


\section{Ethics approval and consent to participate}

Not applicable.

\section{Competing interests}

The authors declare that they have no competing interests.

\section{Publisher's Note}

Springer Nature remains neutral with regard to jurisdictional claims in published maps and institutional affiliations.

\section{Received: 20 September 2017 Accepted: 29 March 2018} Published online: 23 April 2018

\section{References}

1. Gouvea LR, Rubiano LB, Chioratto AF, Zucchi MI, de Souza Goncalves P. Genetic divergence of rubber tree estimated by multivariate techniques and microsatellite markers. Genet Mol Biol. 2010;33(2):308-18.

2. Guardiola-Claramonte M, Troch PA, Ziegler AD, Giambelluca TW, Durcik M, Vogler JB, Nullet MA. Hydrologic effects of the expansion of rubber (Hevea brasiliensis) in a tropical catchment. Ecohydrology. 2010;3(3):306-14

3. Jacob J, Annmalainathan K, Alam BM, Sathick MB, Thapaliyal AP, Devakumar AS. Physiological constraints for cultivation of Hevea brasiliensis in certain unfavourable agroclimatic regions of India. Indian J Nat Rub Res. 1999;12:1-16.

4. Rao PS, Saraswathyamma CK, Sethuraj MR. Studies on the relationship between yield and meteorological parameters of Para rubber tree (Hevea brasiliensis). Agric For Meteorol. 1998:90:235-45.

5. Chinnusamy V, Ohta M, Kanrar S, Lee BH, Hong X, Agarwal M, Zhu JK. ICE1: a regulator of cold-induced transcriptome and freezing tolerance in Arabidopsis. Genes Dev. 2003;17(8):1043-54.

6. Chinnusamy V, Zhu J, Zhu JK. Cold stress regulation of gene expression in plants. Trends Plant Sci. 2007:12(10):444-51.

7. Chinnusamy V, Zhu JK, Sunkar R. Gene regulation during cold stress acclimation in plants. Methods Mol Biol. 2010;639:39-55.

8. Stockinger EJ, Gilmour SJ, Thomashow MF. Arabidopsis thaliana CBF1 encodes an AP2 domain-containing transcriptional activator that binds to the C-repeat/DRE, a cis-acting DNA regulatory element that stimulates transcription in response to low temperature and water deficit. Proc Nat Acad Sci U S A. 1997;94(3):1035-40.

9. Doherty CJ, Van Buskirk HA, Myers SJ, Thomashow MF. Roles for Arabidopsis CAMTA transcription factors in cold-regulated gene expression and freezing tolerance. Plant Cell. 2009;21(3):972-84.

10. Shi Y, Tian S, Hou L, Huang X, Zhang X, Guo H, Yang S. Ethylene signaling negatively regulates freezing tolerance by repressing expression of CBF and type-a ARR genes in Arabidopsis. Plant Cell. 2012;24(6):2578-95.

11. Agarwal M, Hao Y, Kapoor A, Dong CH, Fujii H, Zheng X, Zhu JK. A R2R3 type MYB transcription factor is involved in the cold regulation of CBF genes and in acquired freezing tolerance. J Biol Chem. 2006;281(49):37636.

12. Li H, Ye K, Shi Y, Cheng J, Zhang X, Yang S. BZR1 positively regulates freezing tolerance via CBF-dependent and CBF-independent pathways in Arabidopsis. Mol Plant. 2017:10(4):545-59.

13. Jiang B, Shi Y, Zhang X, Xin X, Qi L, Guo H, Li J, Yang S. PIF3 is a negative regulator of the CBF pathway and freezing tolerance in Arabidopsis. Proc Natl Acad Sci U S A. 2017:114(32):E6695.

14. Miura K, Jin JB, Lee J, Yoo CY, Stirm V, Miura T, Ashworth EN, Bressan RA, Yun DJ, Hasegawa PM. SIZ1-mediated sumoylation of ICE1 controls CBF3/ DREB1A expression and freezing tolerance in Arabidopsis. Plant Cell. 2007 19(4):1403-14.

15. Dong $\mathrm{CH}$, Agarwal M, Zhang Y, Xie Q, Zhu JK. The negative regulator of plant cold responses, HOS1, is a RING E3 ligase that mediates the ubiquitination and degradation of ICE1. Proc Natl Acad Sci U S A. 2006; 103(21):8281-6.

16. Ding Y, Li H, Zhang X, Xie Q, Gong Z, Yang S. OST1 kinase modulates freezing tolerance by enhancing ICE1 stability in Arabidopsis. Dev Cell. 2015; 32(3):278-89.

17. Li H, Ding Y, Shi Y, Zhang X, Zhang S, Gong Z, Yang S. MPK3- and MPK6mediated ICE1 phosphorylation negatively regulates ICE1 stability and freezing tolerance in Arabidopsis. Dev Cell. 2017;43(5):630-42.

18. Liu Z, Jia Y, Ding Y, Shi Y, Li Z, Guo Y, Gong Z, Yang S. Plasma membrane CRPK1-mediated phosphorylation of 14-3-3 proteins induces their nuclear import to fine-tune CBF signaling during cold response. Mol Cell. 2017;66(1): 117-28. e115
19. Chinnusamy V, Schumaker K, Zhu JK. Molecular genetic perspectives on cross-talk and specificity in abiotic stress signalling in plants. J Exp Bot. 2004; 55(395):225-36.

20. Chan Z, Wang Y, Cao M, Gong Y, Mu Z, Wang H, Hu Y, Deng X, He XJ, Zhu JK. RDM4 modulates cold stress resistance in Arabidopsis partially through the CBF-mediated pathway. New Phytol. 2016;209(4):1527-39.

21. Pecinka A, Mittelsten Scheid O. Stress-induced chromatin changes: a critical view on their heritability. Plant Cell Physiol. 2012;53(5):801-8.

22. Probst AV, Mittelsten Scheid O. Stress-induced structural changes in plant chromatin. Curr Opin Plant Biol. 2015;27:8-16.

23. Song Y, Liu L, Feng Y, Wei Y, Yue X, He W, Zhang H, An L. Chilling- and freezing-induced alterations in cytosine methylation and its association with the cold tolerance of an alpine Subnival plant, Chorispora bungeana. PLoS One. 2015;10(8):e0135485

24. Cubas $P$, Vincent $C$, Coen $E$. An epigenetic mutation responsible for natural variation in floral symmetry. Nature. 1999;401(6749):157-61.

25. Johannes F, Porcher E, Teixeira FK, Saliba-Colombani V, Simon M, Agier N Bulski A, Albuisson J, Heredia F, Audigier P, et al. Assessing the impact of transgenerational epigenetic variation on complex traits. PLoS Genet. 2009; 5(6):e1000530.

26. Bewick AJ, Ji L, Niederhuth CE, Willing EM, Hofmeister BT, Shi X, Wang L, Lu Z, Rohr NA, Hartwig B, et al. on the origin and evolutionary consequences of gene body DNA methylation. Proc Natl Acad Sci U S A. 2016;113(32): 9111-6.

27. Law JA, Jacobsen SE. Establishing, maintaining and modifying DNA methylation patterns in plants and animals. Nat Rev Genet. 2010;11(3):204-20.

28. Bewick AJ, Schmitz RJ. Gene body DNA methylation in plants. Curr Opin Plant Biol. 2017:36:103-10

29. Wendte JM, Schmitz RJ. Specifications of targeting heterochromatin modifications in plants. Mol Plant. 2017;

30. Dubin MJ, Zhang P, Meng D, Remigereau MS, Osborne EJ, Paolo, Casale F, Drewe $P$, Kahles A, Jean G, et al. DNA methylation in Arabidopsis has a genetic basis and shows evidence of local adaptation. elife. 2015:4:e05255

31. Cao X, Jacobsen SE. Role of the arabidopsis DRM methyltransferases in de novo DNA methylation and gene silencing. Curr Biol. 2002; 12(13):1138-44.

32. Chan SW, Henderson IR, Jacobsen SE. Gardening the genome: DNA methylation in Arabidopsis thaliana. Nat Rev Genet. 2005:6(5):351-60.

33. Kim YS, Lee M, Lee JH, Lee HJ, Park CM. The unified ICE-CBF pathway provides a transcriptional feedback control of freezing tolerance during cold acclimation in Arabidopsis. Plant Mol Biol. 2015;89(1-2):187-201.

34. Ortega-Galisteo AP, Morales-Ruiz T, Ariza RR, Roldan-Arjona T. Arabidopsis DEMETER-LIKE proteins DML2 and DML3 are required for appropriate distribution of DNA methylation marks. Plant Mol Biol. 2008;67(6):671-81.

35. Penterman J, Zilberman D, Huh JH, Ballinger T, Henikoff S, Fischer RL. DNA demethylation in the Arabidopsis genome. Proc Natl Acad Sci U S A. 2007; 104(16):6752-7.

36. Aufsatz W, Mette MF, van der Winden J, Matzke M, Matzke AJ. HDA6, a putative histone deacetylase needed to enhance DNA methylation induced by double-stranded RNA. EMBO J. 2002;21(24):6832-41.

37. To TK, Kim JM, Matsui A, Kurihara Y, Morosawa T, Ishida J, Tanaka M, Endo T, Kakutani T, Toyoda T, et al. Arabidopsis HDA6 regulates locus-directed heterochromatin silencing in cooperation with MET1. PLoS Genet. 2011;7(4): e1002055.

38. Hu Y, Zhang L, Zhao L, Li J, He S, Zhou K, Yang F, Huang M, Jiang L, Li L. Trichostatin a selectively suppresses the cold-induced transcription of the ZmDREB1 gene in maize. PLoS One. 2011;6(7):e22132.

39. Hu Y, Zhang L, He S, Huang M, Tan J, Zhao L, Yan S, Li H, Zhou K, Liang Y, et al. Cold stress selectively unsilences tandem repeats in heterochromatin associated with accumulation of H3K9ac. Plant Cell Environ. 2012;35(12): 2130-42.

40. Kim JM, Sasaki T, Ueda M, Sako K, Seki M. Chromatin changes in response to drought, salinity, heat, and cold stresses in plants. Front Plant Sci. 2015:6:114.

41. Finnegan EJ, Genger RK, Kovac K, Peacock WJ, Dennis ES. DNA methylation and the promotion of flowering by vernalization. Proc Natl Acad Sci U S A. 1998;95(10):5824-9.

42. Mylne JS, Barrett L, Tessadori F, Mesnage S, Johnson L, Bernatavichute YV Jacobsen SE, Fransz P, Dean C. LHP1, the Arabidopsis homologue of HETEROCHROMATIN PROTEIN1, is required for epigenetic silencing of FLC. Proc Natl Acad Sci U S A. 2006;103(13):5012-7. 
43. Schmitz RJ, Sung S, Amasino RM. Histone arginine methylation is required for vernalization-induced epigenetic silencing of FLC in winter-annual Arabidopsis thaliana. Proc Natl Acad Sci U S A. 2008;105(2):411-6.

44. Mai J, Herbette S, Vandame M, Cavaloc E, Julien JL, Ameglio T, RoeckelDrevet P. Contrasting strategies to cope with chilling stress among clones of a tropical tree, Hevea brasiliensis. Tree Physiol. 2010;30(11):1391-402.

45. Mai J, Herbette S, Vandame M, Kositsup B, Kasemsap P, Cavaloc E, Julien J, Améglio L. Effect of chilling on photosynthesis and antioxidant enzymes in Hevea brasiliensis Muell. Arg. Trees. 2009;23(4):863-74.

46. Richards E, Reichardt M, Rogers S. Preparation of genomic DNA from plant tissue. Current protocols in molecular biology. 2001. Chapter 2:Unit2 3.

47. Tang C, Qi J, Li H, Zhang C, Wang Y. A convenient and efficient protocol for isolating high-quality RNA from latex of Hevea brasiliensis (Para rubber tree). J Biochem Biophys Methods. 2007;70(5):749-54.

48. Wang Y, Guo D, Li HL, Peng SQ. Characterization of HbWRKY1, a WRKY transcription factor from Hevea brasiliensis that negatively regulates HbSRPP. Plant Physiol Biochem. 2013;71:283-9.

49. Li H, Qin Y, Xiao X, Tang C. Screening of valid reference genes for real-time RT-PCR data normalization in Hevea brasiliensis and expression validation of a sucrose transporter gene HbSUT3. Plant Sci. 2011;181(2):132-9.

50. Livak KJ, Schmittgen TD. Analysis of relative gene expression data using real-time quantitative PCR and the 2(-Delta Delta C(T)) method. Methods (San Diego, Calif. 2001;25(4):402-8.

51. Saldanha AJ. Java Treeview-extensible visualization of microarray data. Bioinformatics. 2004;20(17):3246-8.

52. Hong H, Xiao H, Yuan H, Zhai J, Huang X. Cloning and characterisation of JAZ gene family in Hevea brasiliensis. Plant Biol (Stuttg). 2015;17(3):618-24

53. Lescot $M$, Dehais $P$, Thijs $G$, Marchal $K$, Moreau $Y$, Van de Peer $Y$, Rouze $P$, Rombauts S. PlantCARE, a database of plant cis-acting regulatory elements and a portal to tools for in silico analysis of promoter sequences. Nucleic Acids Res. 2002;30(1):325-7.

54. Steward N, Ito M, Yamaguchi Y, Koizumi N, Sano H. Periodic DNA methylation in maize nucleosomes and demethylation by environmental stress. J Biol Chem. 2002:277(40):37741-6.

55. Hetzl J, Foerster AM, Raidl G, Mittelsten Scheid O. CyMATE: a new tool for methylation analysis of plant genomic DNA after bisulphite sequencing. Plant J. 2007;51(3):526-36.

56. Larkin MA, Blackshields G, Brown NP, Chenna R, McGettigan PA, McWilliam $\mathrm{H}$, Valentin F, Wallace IM, Wilm A, Lopez R, et al. ClustalW and ClustalX version 2.0. Bioinformatics. 2007;23:2947-8.

57. Tang C, Yang M, Fang Y, Luo Y, Gao S, Xiao X, An Z, Zhou B, Zhang B, Tan $X$, et al. The rubber tree genome reveals new insights into rubber production and species adaptation. Nat Plants. 2016;2(6):16073.

58. Wang L, Hao L, Li X, Hu S, Ge S, Yu J. SNP deserts of Asian cultivated rice: genomic regions under domestication. J Evol Biol. 2009;22(4):751-61.

59. Al-Mssallem IS, Hu S, Zhang X, Lin Q, Liu W, tan J, Yu X, Liu J, Pan L, Zhang $T$, et al. genome sequence of the date palm Phoenix dactylifera L. Nat Commun. 2013:4:2274

60. Chen B, Cao J, Wang J, Wu Z, Tao Z, Chen J, Yang C, Xie G. Estimation of rubber stand age in typhoon and chilling injury afflicted area with Landsat TM data: a case study in Hainan Island, China. For Ecol Manag. 2012;274: 222-30.

61. Catala R, Salinas J. The Arabidopsis ethylene overproducer mutant eto1-3 displays enhanced freezing tolerance. Plant Signal Behav. 2015;10(3): e989768.

62. Modliszewski JL, Copenhaver GP. Meiotic recombination gets stressed out: CO frequency is plastic under pressure. Curr Opin Plant Biol. 2017;36:95-102.

63. Kumar G, Rattan UK, Singh AK. Chilling-mediated DNA methylation changes during dormancy and its release reveal the importance of epigenetic regulation during winter dormancy in apple (Malus $x$ domestica Borkh.). PLoS One. 2016;11(2):e0149934.

64. Uthup TK, Ravindran M, Bini K, Thakurdas S. Divergent DNA methylation patterns associated with abiotic stress in Hevea brasiliensis. Mol Plant. 2011; 4(6):996-1013.

65. Chinnusamy V, Gong Z, Zhu JK. Abscisic acid-mediated epigenetic processes in plant development and stress responses. J Integr Plant Biol. 2008:50(10):1187-95

66. Choi CS, Sano H. Abiotic-stress induces demethylation and transcriptional activation of a gene encoding a glycerophosphodiesterase-like protein in tobacco plants. Mol Genet Genomics. 2007:277(5):589-600.
67. Hashida SN, Uchiyama T, Martin C, Kishima Y, Sano Y, Mikami T. The temperature-dependent change in methylation of the Antirrhinum transposon Tam3 is controlled by the activity of its transposase. Plant Cell. 2006:18(1):104-18.

68. Chinnusamy V, Zhu JK. Epigenetic regulation of stress responses in plants. Curr Opin Plant Biol. 2009;12(2):133-9.

69. Xie HJ, Li H, Liu D, Dai WM, He JY, Lin S, Duan H, Liu LL, Chen SG, Song XL, et al. ICE1 demethylation drives the range expansion of a plant invader through cold tolerance divergence. Mol Ecol. 2015;24(4):835-50.

70. Lei M, Zhang H, Julian R, Tang K, Xie S, Zhu JK. Regulatory link between DNA methylation and active demethylation in Arabidopsis. Proc Natl Acad Sci U S A. 2015;112(11):3553-7.

\section{Submit your next manuscript to BioMed Central and we will help you at every step:}

- We accept pre-submission inquiries

- Our selector tool helps you to find the most relevant journal

- We provide round the clock customer support

- Convenient online submission

- Thorough peer review

- Inclusion in PubMed and all major indexing services

- Maximum visibility for your research

Submit your manuscript at www.biomedcentral.com/submit
) Biomed Central 